Pignotti, Chiara.

Doctoranda en Arte: Producción e Investigación, Universidad Politécnica de Valencia.

\title{
La doble vida virtual de la Joyería Contemporánea.
}

\author{
TIPO DE TRABAJO \\ Comunicación. \\ PALABRAS CLAVE \\ Joyería Contemporánea; Arte conceptual; Fenómeno mediático.
}

KEY WORDS

Contemporary jewellery; Concept art; Mass media influence.

\section{RESUMEN}

Con el título de joyería contemporánea nos referimos a un fenómeno artístico que nace en Europa en los años 60, a partir de la voluntad por parte de algunos joyeros de renovar el lenguaje en la joyería hacia la libre expresión del artista. En un lapso de tiempo relativamente muy breve se llevó a la joyería a aquellas extremas conclusiones alcanzadas por las artes plásticas, hasta prescindir del cuerpo o del mismo objeto, perdiendo el punto de contacto con la vida diaria.

El primer aspecto de la vida virtual de la nueva joyería es, entonces, la consideración de la "joya" como tema de investigación, contemplación o reflexión, anteponiendo la idea al objeto. Por consiguiente este tipo de joyería vive más a través de medios de comunicación que no le pertenecen, como la fotografía, el vídeo, los textos de comisarios artísticos, cuya propagación exponencial en Internet constituyen el segundo aspecto de su vida virtual: la conversión a fenómeno mediático. La entrada de la joyería contemporánea en las redes telemáticas ha conllevado interesantes cambios sobretodo en los parámetros del mercado de las galerías, y en la exponencial participación de artistas de otros países, gracias a las posibilidades participativas de la Web02.

Proponemos un análisis de estos dos aspectos resaltando que la expansión que este fenómeno tiene a través de la red no ayudó el consolidar de una cultura de la Joyería contemporánea, sino que incluso creó confusión sobre su verdadera naturaleza.

\section{ABSTRACT}

By Contemporary Jewellery we mean an artistic movement, born in Europe in the 60's, developed by some jewellers in order to renovate the language of jewellery towards the artist's freedom of expression.

In a relatively short time jewellery was taken to those extreme conclusions reached by the fine art. In that way jewellery leave aside the relationship with the body or with the objet in itself, losing contact with daily life.

The first aspect of new jewellery's virtual life is the consideration of "jewel" as field of research, contemplation or reflexion, stating the idea before the object.

Hence this kind of jewellery "lives" more through the outside media, such as photography, video, and curatorial texts, which exponential propagation through the Internet builds the second aspect of its virtual life: a conversion into a media phenomenon.

The entrance of Contemporary Jewellery in the web carries interesting changes above all in the gallery market parameters, and the exponential participation of foreign artists because of the participative possibilities of the Web02.

We propose an analysis of these two aspects, pointing out the fact that the expansion of this phenomenon through the net didn't help to consolidate a Contemporary Jewellery culture but, instead, it produced confusion about its real nature. 


\section{CONTENIDO}

\section{Introducción}

Según el diccionario de la real lengua española la joya es en primer lugar "adorno", en segundo lugar menciona su hechura con "metales preciosos" y en último lugar en su mayoría utilizado por "mujeres". Ahora siguiendo estos tres elementos constituyentes de la definición tradicional, podemos decir que la Joyería contemporánea se caracteriza justamente por desvincularse, e incluso en algunos casos, oponerse a ellos.

Con el título de Joyería contemporánea nos referimos a un fenómeno artístico que nace en Europa en los años 60, a partir de la voluntad por parte de algunos joyeros de renovar el concepto, uso y estética de la joyería, hacia la libre expresión del artista, y en relación a los nuevos valores sociales y culturales. Con estas premisas, en un lapso de tiempo relativamente muy breve se llevó a la joyería hasta aquellas extremas conclusiones alcanzadas por las artes plásticas, hasta poder prescindir del cuerpo o del mismo objeto "joya", perdiendo el punto de contacto con la funcionalidad y, por ende, con la vida diaria. Es realmente insólito ver a alguien por la calle portando una pieza de Joyería contemporánea, y son muy pocas las galerías especializadas en este sector. Para la mayoría de las personas, la única manera de ver este tipo de joyería es por medio de Internet, lo cual la convierte en un fenómeno mediático.

\section{Desde la joya como objeto hasta la joya como concepto.}

La Joyería contemporánea se despliega constantemente hacia dos tendencias opuestas y concadenadas entre sí: por un lado está sujeta a una extrema especialización, abstrayendo el objeto joya de su contexto pragmático para insertarlo en discursos conceptuales abstractos. Tal especialización conlleva un continuo estado de auto-referencialidad en el discurso artístico, y carga de un carácter cerrado el circuito - autores, críticos, galeristas - que se ha formado en relación a ella. Por otro lado, la nueva joyería está dispuesta a abrirse, fusionarse y retroalimentarse con cualquier otro campo del saber y del arte, derrumbando cualquier límite categorial.

La joyería, desvinculada así completamente del código y de las categorías tradicionales que le pertenecían, se encuentra en la situación de tener que recrear su propio contexto y lenguaje una y otra vez: cualquier material, objeto o referencia son válidos si se adecua a la intención del joyero. También la misma joyería, y todo lo que le concierne -materiales y técnicas tradicionales, el cuerpo, los símbolos, incluso las herramientas del oficio- llegan a ser considerados elementos formales y conceptuales con los cuales reformular un nuevo y personal código. En este sentido una joya puede ser entonces empleada sólo por su propio significado, como una alianza, que significa claramente el estado civil de una persona, o también como significante, como son las alianzas que componen los eslabones del collar Chain, del joyero suizo Otto Kunzli, confiriendo al espectador una libertad de lecturas múltiples, y dotando la obra de posibilidades dialécticas más amplias.

La intención de Kunzli en esta obra es de una sencillez poética: los elementos que la constituyen, alianzas de segunda mano rescatadas por el artista, tienen un valor simbólico tan fuerte que la obra está más cargada de energía que de significado. La energía emanada por aquellas 48 historias anónimas, que se esconden detrás de cada una de aquellas alianzas, se suma a la energía intrínseca del oro, elemento apotropaico por excelencia, testigo "inmortal" de las vidas humanas perecederas.

Desde el punto de vista objetual esta obra se posiciona en un grado de separación todavía muy leve con respecto a la "joya": es un collar y puede ser cómodamente llevado puesto, sus materiales son tradicionales y duraderos. Empero la experimentación en torno a la joyería se ha extendido hasta los extremos de poder considerar cualquier cosa como tal, como por ejemplo: "si deslizas tu mano

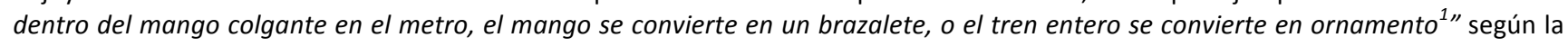
joyera Kerianne Quick. Se da lugar, así, a un vértigo de abstracción que puede llevarnos realmente a cuestionarnos sobre la existencia del "traje del rey".

Queriendo representar gráficamente la amplitud que puede alcanzar el término “joyería” podríamos ubicar la obra de Kunzli casi en el centro, muy cerca del "objeto joya" tradicional. Desde este punto central podemos trazar una serie de círculos concéntricos que nos indican los grados de abstracción objetual, hasta llegar al punto de prescindir de la joya como tal.

En este otro extremo podríamos posicionar, entre otros ejemplos, la obra de Suska Mackert. La artista es de formación joyera, sigue definiéndose como tal aunque desde 1997 dejó de realizar piezas de joyería y se dedicó a obras que se refieren a la joyería como tema de investigación, a través de textos e imágenes. Suska Mackert explica que la suya es una especie de "deformación profesional" que le hacía elegir caminos distintos de la realización de joyería como tal: "desde el puro punto de vista técnico, yo podía realizar buenas piezas de joyería, pero para mi estas piezas no tenían vida, no significaban nada, no tenían carisma. Para mis ojos ellas eran tan bien realizadas, como muertas ${ }^{2 \prime}$.

Muchos de los trabajos conceptuales de Suska Mackert no excluyen el trabajo manual, donde la habilidad y el largo tiempo invertido están considerados por ella parte del significado y valor de su obra. En la instalación 'Ce souvenir sera toujours mon guide, las letras del texto están cubiertas por una especie de nube de cientos de medallitas metálicas completamente recortadas y refinadas a mano ${ }^{3}$; También las que componen el siguiente texto: Materials with a shiny surface reflect light, while else where the light is fully absorbed,

1 GOUDSMIT, L. Jewellery Unleashed. Crossing Borders, 2013. (http://www.premsela.org/en/activities/jewelleryunleashed_1/). (Consultado el 04.05.2015)

2 MACKERT, S. "An object of beauty" En: Thinking Jewellery. On the way towards a theory of jewellery. Ed. Arnoldsche Art Publishers, Alemania, 2011, p.198.

3 DEN BESTER, L. The joy of making the invisible visual by utilising the hand, 2006. (www.klimt02.net/forum/index.php?item_id=4907). (Consultado el 23.04.2015). 
están meticulosamente escritas a mano con pan de oro. Su obra también se caracteriza por ubicarse a menudo en lugares que complementan su significado. El texto en pan de oro fue escrito en el suelo de una tienda de joyería de bajo coste, donde, debido a los pisoteos de los vaivenes de los clientes, el valioso oro se fragmentó, esparciéndose por el espacio, en contradicción con la modestia de la tienda, y borrando a poco a poco lo escrito hasta impedir su lectura ${ }^{4}$.

Entre los dos extremos, de la "joya como objeto" y la "joya como concepto", se produce un continuo feedback que alimenta el pensamiento creativo dentro de la práctica de la joyería. La línea recta que une los dos puntos indica la existencia de un significativo vínculo entre ambos, ya que la idea que dio lugar a otro tipo de expresión artística, nace del trabajo de un joyero, o una joyera, reflexionando sobre el especifico ámbito de la joyería. Este vínculo justifica la consideración de estas obras como Joyería contemporánea, y su presencia en galerías exclusivas de joyería o museos de diseño o artes aplicadas.

El primer aspecto de la vida virtual de la Joyería contemporánea es, por lo tanto, la trasformación del "objeto joya" en "tema de reflexión", del cual surgen obras que pueden prescindir tanto del cuerpo como del objeto. Por consiguiente la mayoría de este tipo de joyería existe través de medios que no le pertenecen, como la fotografía, el vídeo, los catálogos y textos de comisarios artísticos, cuya propagación exponencial en Internet constituyen el segundo aspecto de su vida virtual: la conversión a fenómeno mediático.
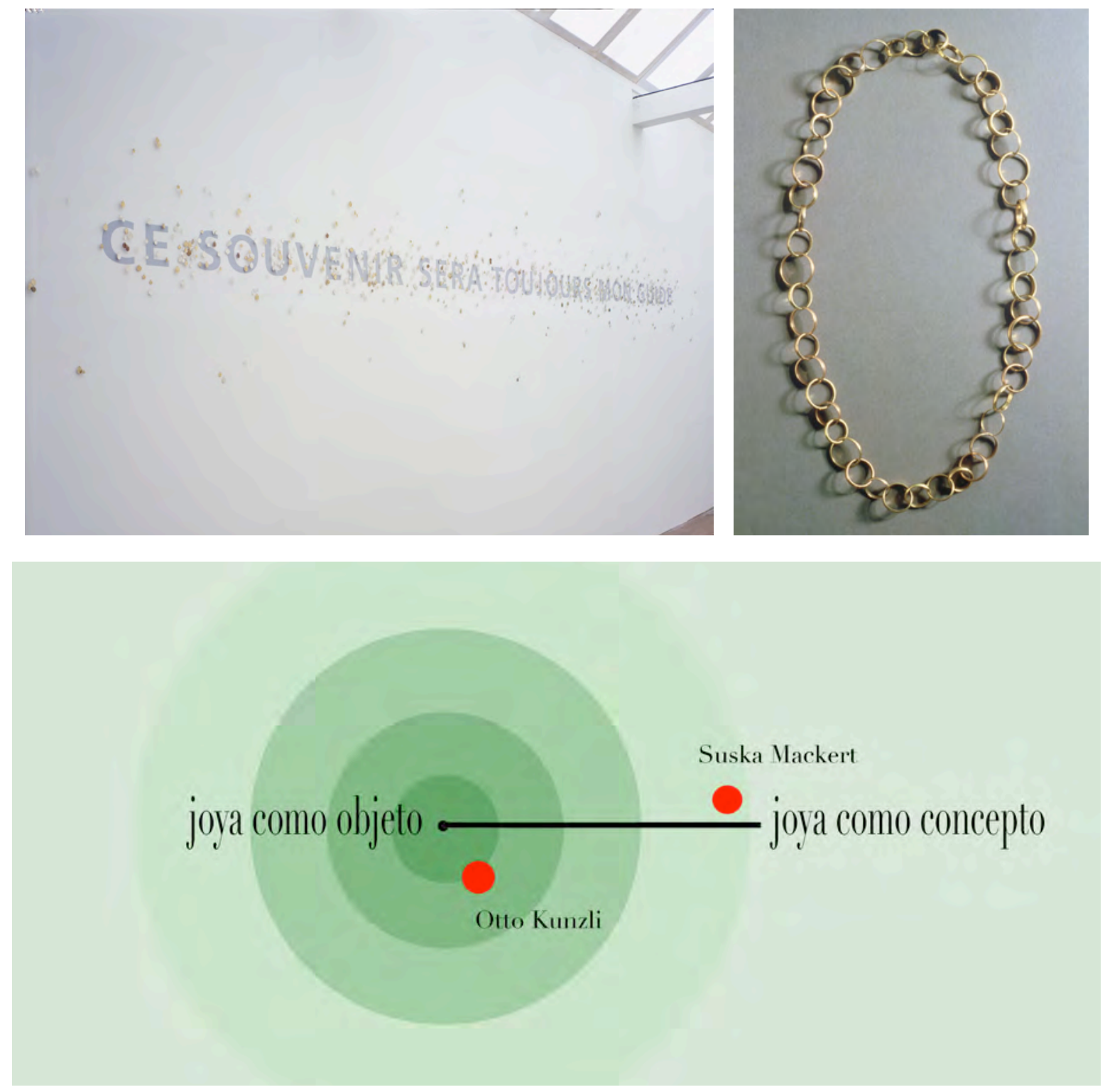

Ilustración 1. Suska Mackert, 'Ce souvenir sera toujours mon guide, 2004. Otto Kunzli, Chain, 1985.

4 JONSSON, L. Images, codes and poetry: the jewellery of Suska Mackert, 2006. (klimt02.net/forum/articles/images-codesand-poetry-the-jewellery-of-suska-mackert). (Consultado el 23.04.2015). 


\section{El fenómeno mediático.}

Inicialmente el restringido circuito Joyería contemporánea estaba circunscrito sólo a algunos centros, ubicados principalmente en Europa, donde las pocas galerías, revistas y algunas publicaciones eran el único medio de visibilidad para los comprometidos con esta nueva expresión artística.

La expansión global de la Joyería contemporánea fue posible sólo gracias al desarrollo de la posibilidad participativa de la Web 2.0. La gran diferencia de la segunda generación de la World Wide Web, respecto a la anterior es la posibilidad que ésta otorga a cualquier usuario de generar y propagar información en la red. Como explica Juan M. Prada, "si antes los grandes portales de internet eran enormes fuentes de información que generaban sus equipos profesionales de desarrollo de contenidos, las empresas que prosperaran en la Web 2.0 lo que harán es servirse de la información y contenidos aportados por sus propios usuarios. Ahora todo se fundamentará en una permanente llamada a la participación y al intercambio". Dicha "llamada a la participación y al intercambio" abrió los confines geográficos de la Joyería Contemporánea, permitiendo la entrada de nuevos artistas desde países "periféricos", garantizándole una constante conexión entre ellos, constituyendo lo que podríamos definir como "gremio mundial".

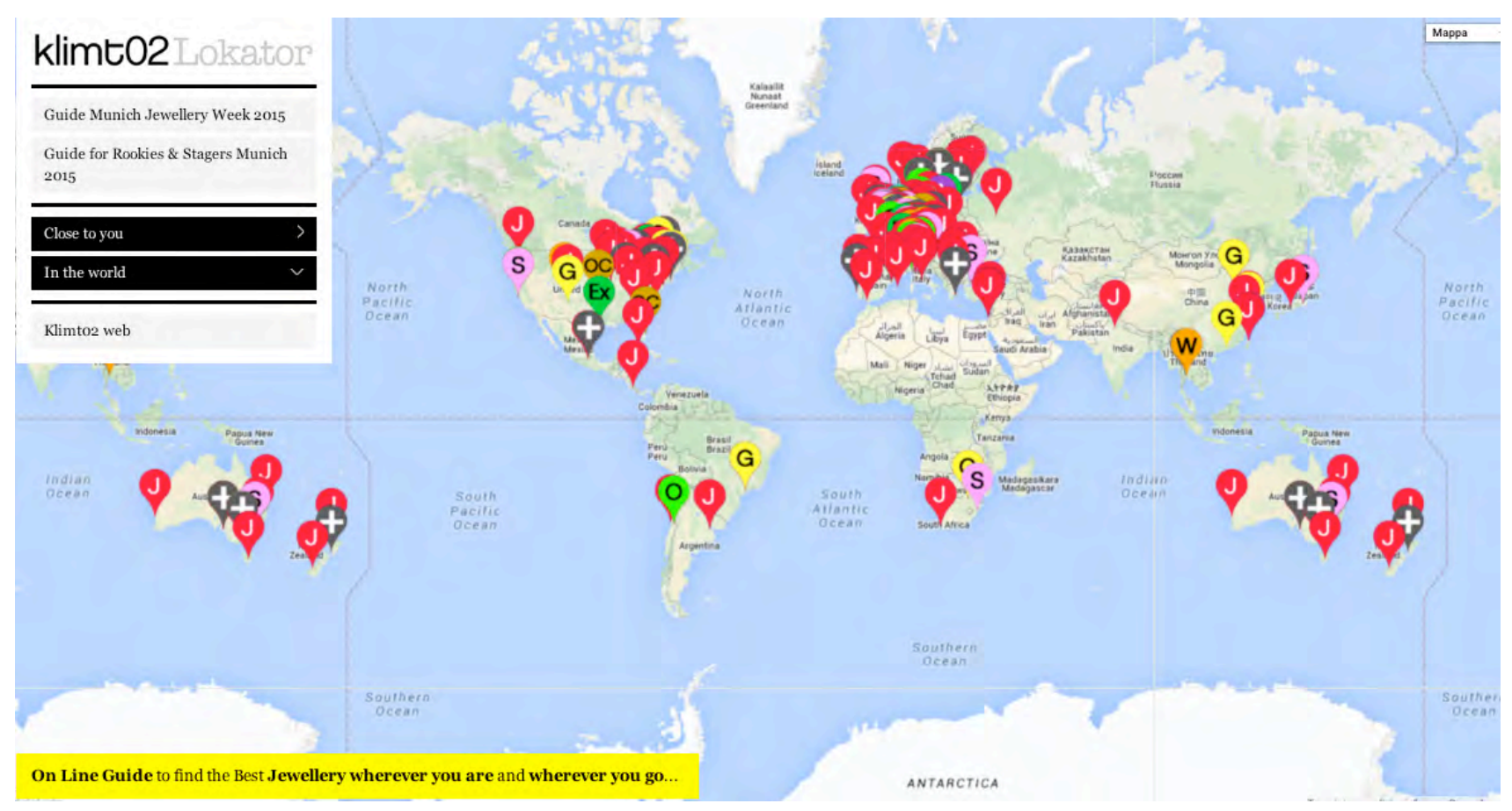

llustración 2. Mapa del circuito de la Joyería Contemporánea en el mundo.

Para los joyeros la conexión se volvió un factor fundamental para su trabajo, como Juan M. Prada explica: "el estar conectado casi de forma permanente y ser usuario de las plataformas y redes sociales más conocidas está dejando de ser una opción para convertirse en un estado necesario, en una condición para la no exclusión" ${ }^{\prime \prime}$. Los joyeros tienen que poner su atención y dedicar tiempo a su presencia mediática ya que de esto principalmente depende la popularidad de su obra.

Algunos críticos denuncian que hasta incluso el networking ha llegado a ser el principal parámetro de selección para las galerías. El artista Daniel Buren en el artículo The Funcion of the Gallery ${ }^{7}$, realiza una interesante reflexión sobre el rol de las galerías en la era telemática, donde resulta evidente que las galerías de joyería ya no se atreven a apostar en obras de desconocidos, sino que invitan a los artistas que ya tengan notoriedad gracias a la red. Por tanto, concluye Buren, el networking tiene efectivamente una importancia mayor de la evaluación objetiva de la calidad de la obra, sobretodo en un contexto artístico como el de la Joyería contemporánea que carece de un sólido y unívoco discurso crítico.

5 PRADA, J. M. Practicas artísticas e internet en la época de las retes sociales. Ed. Akal, Madrid, 2012. Pág. 26. 6 lbídem.

7 BUREN, D. The Function of the Galery, 2008.

(www. conceptualmetalsmithing.com/2008/11/function-of-gallery-daniel-burenredux.h tm I). ( Consultado el 22/03/2015). 
La Joyería contemporánea se ha transformado, entonces, en una carrera a la visibilidad mediática de los autores y de sus obras, empero sin ninguna formulación de ningún conocimiento más profundo por parte del público que pueda favorecer un criterio de juicio o selección. La híper-difusión de las imágenes resta tiempo al entendimiento, análisis y reflexión, desfavoreciendo el pensamiento crítico, creando la ilusión de que todo vale, todo es accesible y nada cuesta esfuerzo. Dicha ilusión aumenta a medida que nos alejamos del "centro" donde se produce el fenómeno. El conocimiento que se puede tener a través de Internet de las obras es parcial, irreal y superficial, ya que excluye la relación sensorial con el cuerpo, en la cual cuenta el peso, el tamaño, la forma, la sensación táctil de los materiales etc. Por tanto, cuanto más geográficamente alejados de los centros donde este tipo de joyería se pueda ver y tocar estén los joyeros, donde se formula el debate entre artistas para conocer sus intenciones y el contexto de donde surgió la pieza, tanto más se consigue una gran confusión sobre su verdadera naturaleza. Esta falta de experiencia puede inducir a un desentendimiento o a una malinterpretación de la pieza. Se generan paradójicamente dos efectos opuestos, por un lado la banalización de las obras privadas de su corporalidad y contexto, a la vez que hay una sobrestimación de las mismas, por efecto del circo mediático, es decir, la tendencia de los mass media a transformar las cosas, personas y acontecimientos en un espectáculo, en algo atractivo que se quiere tener o al cual se quiere pertenecer.

\section{Conclusiones}

La conceptualización de la Joyería podría ser considerada como el resultado de aquel parangone renacentista que tanto ha influido sobre la cultura occidental en la consideración del trabajo intelectual como superior al trabajo manual, que subordinó las artesanías a las bellas artes. Esta situación alimenta el debate entre los joyeros, sobre hasta qué punto se puede hablar de joyería cuando se trata de obras tan lejanas del "objeto joya". El debate se complica cuando se formula en culturas no occidentales donde la experiencia de la Joyería contemporánea es algo adquirido, importado desde afuera. El hecho de que la nueva postura frente a la concepción de joyería sea aprendida principalmente por medio de Internet, conlleva malinterpretaciones y el riesgo de la emulación, o por el contrario comporta una incomprensión y por tanto un rechazo, sobretodo por parte de los joyeros tradicionales. Podemos concluir que la sobreexposición de la Joyería contemporánea en la red no mejoró su conocimiento por parte de los joyeros ni mucho menos por el público en general; al contrario aumentó la confusión con otras ramas de la joyería cuyos autores empezaron a adoptar el apelativo "contemporánea" a medida que esta expresión se difundía en la red.

Recordamos a Jean Baudrillard cuando afirma que "nada desaparece ya por su final o por su muerte, sino por su proliferación, contaminación, saturación, sino un modo fractal de dispersión (...) la lógica de la dispersión viral de las redes ya no es la del valor, ni, por tanto, la de la equivalencia. Ya no hay revolución, sino una circunvolución, una involución del valor." ${ }^{8}$ Sin duda parece ser ésta la suerte de la Joyería contemporánea en la actualidad.

\section{FUENTES REFERENCIALES.}

BUREN, D. The Function of the Galery, 2008. (www.conceptualmetalsmithing.com/2008/11/function-of-gallery-daniel-burenredux.html).(Consultado el 22/03/2015).

DEN BESTER, L. The joy of making the invisible visual by utilising the hand, 2006. (www.klimt02.net/forum/index.php?item_id=4907). (Consultado el 23.04.2015).

DEN BESTEN L. On Jewellery. A compendium of international contemporary art jewellery. Alemania. Ed. Arnoldsche, 2012.

JONSSON, L. Images, codes and poetry: the jewellery of Suska Mackert, 2006. (klimt02.net/forum/articles/images-codes-and-poetrythe-jewellery-of-suska-mackert). (Consultado el 23.04.2015).

LINDEMANN W. Thinking Jewellery. On the way towards a theory of jewellery. Alemania. Arnoldsche Art Publishers, 2011.

PRADA, J. M. Practicas artísticas e internet en la época de las retes sociales. Ed. Akal, Madrid, 2012.

8 BAUDRILLARD, J. La trasparenza del male. Saggio sui fenomeni estremi. Ed. SugarCo, Milano, 1996, p.10. 